\title{
The Effect of Cost-share Programs on Ground Water Exploitation and Nonpoint-source Pollution under Endogenous Technical Change
}

\author{
C. S. Kim and Todd Guilfoos
}

\begin{abstract}
Empirical studies suggest that cost-share programs are unlikely to reduce exploitation of ground water and nonpoint-source pollution. By introducing an induced irrigation technology in our model, we find theoretically that the optimal amount of irrigation water and nitrogen fertilizer increases (decreases) when the increased rate of the marginal net economic benefits from their use with an induced irrigation technology exceeds (is less than) an increase in the rate of irrigation efficiency. Our results suggest that producers should use relatively more irrigation water and fertilizer when greater quantities of high-value crops are grown because producers will adopt improved irrigation technologies for such crops.
\end{abstract}

Key Words: cost-share program, ground water exploitation, induced irrigation technology, nonjoint production, nonpoint-source pollution

Managing exploitation of ground water for agriculture and controlling nonpointsource pollution for public health have long been important issues for economists and agricultural policymakers. In response to growing public concern about ground water depletion and nonpoint-source contamination, the U.S. Congress established, as part of the 1996 Farm Act, an agricultural cost-share program known as the Environmental Quality Incentive Program (EQIP) to encourage producers to adopt resource-conserving and environmentally beneficial agricultural practices. However, there were some changes to EQIP in the 2008

C. S. Kim is a senior economist at the Economic Research Service, U.S. Department of Agriculture and Todd Guilfoos is an assistant professor in the Department of Environmental and Natural Resource Economics at University of Rhode Island. Seniority is not assigned. Correspondence: C. S. Kim " Economic Research Service - Conservation and Environment Branch " 355 E. Street, SW, Washington, DC 20024 - Phone 202.694.5545 - Email ckim@ers.usda.gov.

The authors are indebted to two anonymous reviewers for their valued comments and suggestions on an earlier draft and thank Keith Fuglie, Steve Wallander, and Seth Wechsler at the Economic Research Service, U.S. Department of Agriculture (USDA), for their comments on an earlier draft. The views expressed are the authors' and do not necessarily represent the policies or views of the USDA or Economic Research Service.

Agricultural and Resource Economics Review 45/2 (August 2016) 394-417

(C) The Author(s) 2016. This is an Open Access article, distributed under the terms of the Creative Commons Attribution-NonCommercial-ShareAlike licence (http://creativecommons.org/licenses/ by-nc-sa/4.0/), which permits non-commercial re-use, distribution, and reproduction in any medium, provided the same Creative Commons licence is included and the original work is properly cited. The written permission of Cambridge University Press must be obtained for commercial re-use. 
Farm Bill. ${ }^{1}$ For applications that included water conservation or irrigationefficiency conservation practices, the 2008 Farm Bill required the Natural Resources Conservation Service (NRCS) to give priority to applications that demonstrated a reduction in water use by the agricultural operation: ${ }^{2}$

As a condition of receiving a higher ranking with the grouping of water conservation applications, the producer agrees not to use any associated water savings to bring new land under irrigation production, excluding incidental land needed for efficient operations. (Section 2503-Environmental Quality Incentives Program)

Irrigation practices that improved the efficiency of water use included precision irrigation systems, automation of irrigation systems, and newer sensorcontrolled equipment (Lichtenberg, Majsztrik, and Saavoss 2015).

Since then, numerous studies have analyzed agricultural cost-sharing programs using a variety of models, including dynamic models of management of exploitation of ground water and nonpoint-source pollution (Wu et al. 1994, Kim, Schaible, and Daberkow 2000), mathematical programming models for conservation of irrigation water (Huffacker and Whittlesey 2003, Scheierling, Young, and Cardon 2006), risk-programming models for conservation of ground water (Peterson and Ding 2005), and multi-year optimization models for conservation of ground water (Ward et al. 2008).

While numerous empirical studies have suggested that cost-sharing programs are unlikely to reduce either use of irrigation water or nonpoint-source pollution (Huffaker and Whittlesey 2003, Pfeiffer and Lin 2014, Ward et al. 2008, Wu et al. 1994), a few studies have provided some support for cost-sharing programs by demonstrating that optimal applications of irrigation and fertilization do not respond monotonically to changes in the efficiency of the irrigation system. Peterson and Ding (2005) found that an irrigation system that provides intermediate efficiency (sprinklers) results in greater water use while a highefficiency irrigation system (drip) results in less use of water than an inefficient flood irrigation system. Similarly, Kim, Schaible, and Daberkow (2000) found that adoption of cost-shared center-pivot systems reduces contamination of ground water while other irrigation systems (tail-water recovery and surge flow) result in continued deterioration of the quality of ground water. The changes in the EQIP program in 2008 reduce conversion of acres from dryland to irrigated operations involving high-value crops, potentially changing the results found in prior studies.

We revisit the effects of the EQIP cost-share program on conservation of ground water and management of nonpoint-source pollution by ameliorating the shortcomings of the hydrologic and economic models used in previous

\footnotetext{
1 See the U.S. Department of Agriculture Natural Resources Conservation Service 2014 publication "Subsurface Drip Irrigation: Conservation Today for Water Tomorrow."

${ }_{2}$ An example is the Precise Mobil Drip Irrigation (PMDI ${ }^{\mathrm{IM}}$ ) system patented by T-L Irrigation Company in Nebraska (Bordovsky 2015).
} 
studies, in which (i) a partial analysis was associated with the effects of the costshare program on either conservation of ground water or nonpoint-source pollution but not both, (ii) economic benefits from irrigation water and nitrogen fertilizer uses were overestimated, (iii) the delayed response associated with nitrate leaching and ground water return flows was omitted, (iv) critical elements of the nutrient cycle were omitted, and, most importantly, (v) the process of developing and adopting induced irrigation technologies was omitted.

Induced technical changes in irrigation systems occur in response to government policies and market conditions. Once such a technology is developed, producers typically delay adopting it if the net economic benefit from the new technology is lower than the net benefit of conventional technologies. Despite strong evidence that government policies and market conditions influence the direction of technological change, the development and subsequent adoption of induced irrigation technologies have not been examined as a means of protecting aquifers from over-exploitation and nonpoint-source nitrate contamination. Most of the earlier studies of irrigation technologies dealt with either adoption (Burness and Brill 2001, Ashwell and Peterson 2013, Shah, Zilberman, and Chakravorty 1995) or development (Kim et al. 1996) but not both.

To endogenize the timing of development and adoption of new irrigation systems in the future, we employ a hazard-function approach in which the probabilities of developing and adopting a new irrigation technology are influenced by the cost of adopting the new system. When the private benefit is insufficient to encourage voluntary adoption, the public sector may be justified in sharing the cost of adoption, particularly if the combined public and private benefits exceed the adoption cost. ${ }^{3}$

We derive the socially optimal rate of cost-share that would encourage the irrigation industry to develop improved technologies and encourage producers to adopt the induced technical change in irrigation system. We further evaluate the effect of the subsidy on ground water exploitation and nonpoint-source nitrate pollution. Our model suggests that whether producers generate greater water pollution when they adopt the improved irrigation technology depends on whether the increased rate of irrigation efficiency is greater or smaller than the increased rate of the marginal net economic benefit.

We discuss the economic benefits of adopting an improved irrigation technology on demand for ground water and nitrogen fertilizer and explicitly account for changes in input-use efficiency. We then introduce development of an induced irrigation technology in which irrigation enterprises respond to

3 When the private benefit is insufficient to cover the cost of adopting an improved irrigation technology, cost-share programs would work as market-clearing instruments by shifting the farmers' demand function (i.e., adoption) for new irrigation technology upward. 
a rising cost for pumping of ground water and a government subsidy granted in response to society's willingness to pay to avoid depletion of ground water and to protect water quality by allocating research and development (R\&D) funds to more-efficient irrigation systems. After development of an induced irrigation technology, the extent to which farmers are likely to adopt it depends largely on the net economic benefit resulting from its installation and maintenance. Therefore, a subsidy rate, such as the one provided by EQIP, is incorporated into the farmer's adoption decision.

Since exploitation of ground water involves use of a finite natural resource, we present a dynamic model of ground water and fertilizer use for irrigated crop production. The model incorporates consumptive-equivalent uses of irrigation water and nitrogen fertilizer ${ }^{4}$ as well as critical elements of the nutrient cycle and the delayed responses of return flows of water and nitrate leaching to the aquifer. We also incorporate uncertainty in the dates of development and adoption of the induced irrigation technology.

\section{Economic Benefits from Irrigation-water and Nitrogen-fertilizer Applications}

Traditional crop-production functions assume that all of the variable inputs, including irrigation water and nitrogen fertilizer, are fully employed to produce the crop output. ${ }^{5}$ If crop production and nonpoint-source pollution are characterized by jointness in output, a crop-production function cannot be estimated (Shumway, Pope, and Nash 1983). Therefore, the cropproduction process and generation of nonpoint-source pollution are moreappropriately characterized as nonjoint production processes (Kohli 1983, Kim, Schaible, and Daberkow 2000). And since nitrates are highly soluble in water and are transported into aquifers through return flows of irrigation water, both over-exploitation of ground water for irrigation and deterioration in the quality of ground water from transported nutrients may be managed by adopting irrigation technologies that use water more efficiently.

Aggregate production functions for estimating crop responses across fields or regions with heterogeneity or nonuniformities in the distribution of inputs such as irrigation water and nitrogen fertilizer result in smooth nonlinear functions that are concave with positive marginal products (Berck and Helfand 1990). Therefore, we assume that the crop-production function is quadratic so that the linear factor-demand functions are tractable mathematically. The

\footnotetext{
4 Consumptive-equivalent is defined as the application rate of irrigation water multiplied by the rate of irrigation efficiency.

5 Most prior studies considered management of either quantity or quality of ground water but not both. Exceptions are Roseta-Palma (2003) and Wu et al. (1994), which used conventional dynamic models of ground water management.
} 
crop-production function based on consumptive use of irrigation water, $W^{*}(t)$, and consumptive use of nitrogen fertilizer, $n^{*}(t)$, is then represented by

$$
\begin{aligned}
Y\left(W^{*}(t), n^{*}(t)\right)= & a_{0}+a_{1} W^{*}(t)-a_{2}\left(W^{*}(t)\right)^{2}+a_{3} n^{*}(t) \\
& -a_{4}\left(n^{*}(t)\right)^{2}+a_{5} W^{*}(t) n^{*}(t)
\end{aligned}
$$

where $Y$ is output, $W^{*}(t)$ and $n^{*}(t)$ are the consumptive use of irrigation water and nitrates, respectively, and $a_{i}(i=0,1, \ldots 5)$ are positive parameters.

Since the producer's costs for pumping and of fertilization are based on the rates of irrigation water $(W)$ and fertilizer $(n)$ applied, it is more convenient to present the crop-production function (equation 1) in terms of the rates of consumptive-equivalent irrigation water and nitrogen fertilizer applied. Since nitrates are highly soluble in water and are transported to aquifers in irrigation water, we assume that the fertilization efficiency is the same as the irrigation efficiency to reduce complexity.

Let $\alpha_{0}>0$ be the rate of efficiency of the current irrigation technology such that a linear transformation of the use of irrigation water (IW) is represented by $W^{*}(t)=\alpha_{0} W_{0}(t)$ where $W_{0}$ is the rate of IW applied using the current irrigation technology. Similarly, the fertilization efficiency associated with the current irrigation technology is represented by $n^{*}(t)=\alpha_{0}\left[n_{0}(t)+f_{0} N(t)\right]$ where $n_{0}(t)$ is the amount of nitrogen fertilizer (NF) applied using the current irrigation technology, $N(t)$ is the nitrate stock in the aquifer, and $f_{0}$ is a fractional coefficient representing the ratio of IW using the current irrigation technology to the volume of water in the aquifer so that $f_{0} N(t)$ represents the concentration of nitrates in the IW (i.e., the nutrient recycle). ${ }^{6}$ The crop-production function (equation 1), which is based on the consumptive-equivalent rate of application of IW and NF, is then rewritten as

$$
\begin{aligned}
Y\left(\alpha_{0} W_{0}(t), \alpha_{0}\left(n_{0}(t)+f_{0} N(t)\right)\right)= & a_{0} \\
& +a_{1} \alpha_{0} W_{0}(t)-a_{2} \alpha_{0}^{2}\left[W_{0}(t)\right]^{2} \\
& +a_{3}\left[n_{0}(t)+f_{0} N(t)\right] \\
& -a_{4} \alpha_{0}^{2}\left[n_{0}(t)+f_{0} N(t)\right]^{2} \\
& +a_{5} \alpha_{0}^{2} W_{0}(t)\left[n_{0}(t)+f_{0} N(t)\right] .
\end{aligned}
$$

The marginal benefits from the consumptive use of IW and NF differ from the marginal benefits associated with the application rates for IW and NF. Let the

\footnotetext{
6 In fact, $f_{0}$ changes over time as the stock of ground water and use of IW change (see Kim,
} Schaible, and Daberkow 2000). However, we assume a constant fraction for simplicity. 
linear transformation of the marginal benefit from consumptive use of IW be represented by

$$
P_{w^{*}}=\frac{P_{w_{0}}}{\alpha_{0}}
$$

where $P_{w^{*}}$ and $P_{w 0}$ are the marginal benefits from IW based on the consumptive use and the application rate, respectively. A linear transformation of the marginal benefit from use of NF is represented by

$$
P_{n^{*}}=\frac{P_{n_{0}}}{\alpha_{0}}
$$

where $P_{n^{*}}$ and $P_{n 0}$ are the marginal benefits from NF based on the consumptive use and the application rate, respectively.

The consumptive-equivalent inverse IW and NF demand functions are then represented by ${ }^{7}$

$$
\frac{P_{w_{0}}}{\alpha_{0}}=P_{y} \alpha_{0}\left\{\left[a_{1}+a_{5} \alpha_{0}\left(n_{0}(t)+f_{0} N(t)\right)\right]-2 a_{2} \alpha_{0} W_{0}(t)\right\}
$$

or, equivalently,

$$
P_{w_{0}}=P_{y} \alpha_{0}^{2}\left\{\left[a_{1}+a_{5} \alpha_{0}\left(n_{0}(t)+f_{0} N(t)\right)\right]-2 a_{2} \alpha_{0} W_{0}(t)\right\} .
$$

Similarly, the inverse NF demand based on consumptive-equivalent NF use is obtained using equation 2 as follows:

$$
\frac{P_{n_{0}}}{\alpha_{0}}=P_{y} \alpha_{0}\left\{\left[a_{3}-2 a_{4} \alpha_{0} f_{0} N(t)+a_{5} \alpha_{0} W_{0}(t)\right]-2 a_{4} \alpha_{0} n_{0}(t)\right\}
$$

or, equivalently,

\footnotetext{
7 Both consumptive use of IW, $W^{*}(t)$, and the marginal benefit from consumptive use of IW, $P_{w^{*}}$, must be linearly transformed using the irrigation efficiency rate to measure the economic benefit based on the irrigation application rate (Kim and Schaible 2000, Kim, Schaible, and Daberkow 2000). Omission of the linear transformation of $P_{w^{*}}$ leads to overstatement of the economic benefit from use of IW and to the magnitude of estimation bias being proportional to the rate of irrigation inefficiency. Studies that avoided such bias include Peterson and Ding (2005) and Pfeiffer and Lin (2014), which used direct profit-maximization models.
} 


$$
P_{n_{0}}=P_{y} \alpha_{0}^{2}\left\{\left[a_{3}-2 a_{4} \alpha_{0} f_{0} N(t)+a_{5} \alpha_{0} W_{0}(t)\right]-2 a_{4} \alpha_{0} n_{0}(t)\right\}
$$

Using equations $3^{\prime}$ and $4^{\prime}$, the economic benefits from IW and NF use are represented in equations 5 and 6, respectively.

$$
\begin{aligned}
B\left(W_{0}: P_{w_{0}}\right) & =\int_{0}^{W_{0}(t)} P_{y} \alpha_{0}^{2}\left\{\left[a_{1}+a_{5} \alpha_{0}\left(n_{0}(t)+f_{0} N(t)\right)\right]-2 a_{2} \alpha_{0} x\right\} d x \\
& =P_{y} \alpha_{0}^{2}\left\{\left[a_{1}+a_{5} \alpha_{0}\left(n_{0}(t)+f_{0} N(t)\right)\right] W_{0}(t)-a_{2} \alpha_{0} W_{0}^{2}(t)\right\} \\
B\left(n_{0}: P_{n_{n}}\right) & =\int_{0}^{n_{0}(t)} P_{y} \alpha_{0}^{2}\left\{\left[a_{3}+a_{5} \alpha_{0} W_{0}(t)-2 a_{4} \alpha_{0} f_{0} N(t)\right]-2 a_{4} \alpha_{0} x\right\} d x \\
& =P_{y} \alpha_{0}^{2}\left\{\left[a_{3}+a_{5} \alpha_{0} W_{0}(t)-2 a_{4} \alpha_{0} f_{0} N(t)\right] n_{0}(t)-a_{4} \alpha_{0} n_{0}^{2}(t)\right\}
\end{aligned}
$$

As producers adopt improved irrigation systems, the inverse demand curves for IW and NF shift to either the right or the left. To investigate whether adoption of an efficient irrigation technology would lead to increased or decreased use of IW, the differential of equation $3^{\prime}$ with respect to the efficiency rate, $\alpha_{0}$, is given in equation 7 :

$$
\begin{gathered}
{\left[\frac{\partial W_{0}(t)}{\partial \alpha_{0}}-\frac{\partial W_{0}(t)}{\partial n_{0}(t)}\left(\frac{\partial n_{0}(t)}{\partial \alpha_{0}}\right)\right]=} \\
=\frac{1}{\alpha_{0}}\left(\frac{\partial W_{0}(t)}{\partial P_{w_{0}}}\right)\left[P_{y} a_{1} \alpha_{0}^{2}+P_{w_{0}}(\eta-3)\right] \\
>=<0
\end{gathered}
$$

where

$$
\eta=\frac{\partial P_{w_{0}}}{\partial \alpha_{0}} \frac{\alpha_{0}}{P_{w_{0}}}
$$

is the technology elasticity of the marginal benefit of IW or, equivalently,

$$
\left[\frac{\partial W_{0}(t)}{\partial \alpha_{0}}-\frac{\partial W_{0}(t)}{\partial n_{0}(t)}\left(\frac{\partial n_{0}(t)}{\partial \alpha_{0}}\right)\right]>=<0 \quad \text { if } \quad \eta<=>\left[3-\frac{P_{y} a_{1} \alpha_{0}^{2}}{P_{w_{0}}}\right] .
$$

The lefthand side of the equality in equation $7^{\prime}$ represents the aggregate marginal change in use of IW as the irrigation efficiency changes. The first and second terms represent the direct and indirect (through a complementary input) marginal change in use of IW. The result from $7^{\prime}$ indicates that the demand curve for IW shifts to the right (left) as irrigation 
efficiency improves (declines) depending on whether the change in the rate of the marginal benefit of IW when the change in irrigation efficiency is less than (greater than)

$$
\left[3-\frac{P_{y} a_{1} \alpha_{0}^{2}}{P_{w_{0}}}\right]
$$

Similarly, the differential of equation $4^{\prime}$ with respect to the rate of irrigation efficiency, $\alpha_{0}$, is given by

$$
\begin{aligned}
{\left[\frac{\partial n_{0}(t)}{\partial \alpha_{0}}-\frac{\partial n_{0}(t)}{\partial W_{0}(t)}\left(\frac{\partial W_{0}(t)}{\partial \alpha_{0}}\right)\right]=} & \frac{1}{\alpha_{0}}\left(\frac{\partial n_{0}(t)}{\partial P_{n_{0}}}\right)\left[P_{y} a_{3} \alpha_{0}^{2}+P_{n_{0}}(\varepsilon-3)\right] \\
& >=<0
\end{aligned}
$$

where

$$
\varepsilon=\frac{\partial P_{n_{0}}}{\partial \alpha_{0}} \frac{\alpha_{0}}{P_{n_{0}}}
$$

is the technology elasticity of the marginal benefit of NF. Equation 8 can be rewritten as

$$
\left[\frac{\partial n_{0}(t)}{\partial \alpha_{0}}-\frac{\partial n_{0}(t)}{\partial W_{0}(t)}\left(\frac{\partial W_{0}(t)}{\partial \alpha_{0}}\right)\right]>=<0 \quad \text { if } \quad \varepsilon<=>\left[3-\frac{P_{y} a_{3} \alpha_{0}^{2}}{P_{n_{0}}}\right]
$$

The result in $8^{\prime}$ also indicates that the demand function for NF would shift right (left) as an improved irrigation technology is adopted depending on whether the rate of increase of the marginal benefit of NF is less than (greater than)

$$
\left[3-\frac{P_{y} a_{3} \alpha_{0}^{2}}{P_{n_{0}}}\right]
$$

The results in equations $7^{\prime}$ and $8^{\prime}$ provide some indication of whether use of IW and NF increases or decreases because of adoption of an improved irrigation technology. However, those equations are derived from the inverse demand functions for IW and NF in equations $3^{\prime}$ and $4^{\prime}$, respectively, and any economic interpretation that is based on factor-demand functions can be somewhat misleading because those functions do not account for the process 
of adoption of technology. Therefore, we use the optimal economic properties of use of IW and NF to further examine how producers adapt their use of IW and $\mathrm{NF}$ when they adopt improved irrigation technologies.

\section{Development and Adoption of Induced Irrigation Technologies}

\section{Development}

Irrigation enterprises respond to the economic and policy incentives provided to producers. ${ }^{8}$ Endogenous technological changes can be assigned to one of two broad, disjointed categories: invention and learning by doing (Romer 1990, 1994, Young 1993). We focus on development of new irrigation technologies through deliberate research by government agencies, academics, and irrigation enterprises to resolve regional problems. As a factor of production (IW in this case) becomes increasingly scarce (more costly) and government agencies subsidize the cost of adopting more-efficient irrigation technologies, irrigation enterprises allocate more $R \& D$ resources to developing technologies that save or substitute for the scarce resource (Hayami and Ruttan 1985, Kamien and Schwartz 1978, Kim et al. 1996). We do not distinguish between public and private research as the efforts are often collaborative (Center for Irrigation Technology 2015, Irrigation Association 2015, Irrigation Technology Center 2015).

In our dynamic framework of ground water management, we use a hazard function to explain development of an induced irrigation technology. ${ }^{9} \mathrm{We}$ assume that the probability of developing technology $i$ at a given point in time (prior to that technical innovation occurring) is an increasing function of (i) the capital stock $\left(K\left(t \mid k, g_{i}\right)\right)$ of irrigation system manufacturers, ${ }^{10}$ which depends on the cost of energy to pump one acre-foot of ground water per foot of lift $(k)$ and the government subsidy rate to producers to adopt improved irrigation technologies $\left(g_{i}\right)$, and (ii) the amortized annual unit price of an induced irrigation system $\left(z_{i}(t)\right) \cdot{ }^{11}$

8 According to Bordovsky (2015), who invented the Low Energy Precision Application (LEPA) system, the irrigation industry makes capital investments to resolve regional problems rather than national or international problems: "A logic follows that a solution for a specific regional problem would likely be applicable to other regions or globally at some point in the future."

9 Use of a hazard-function approach while considering uncertainty of the timing of innovation derived from research investments was first suggested by Kieffer (1988), and Kim et al. (2010) applied a hazard-function approach associated with development and adoption of innovative technology in managing invasive species.

10 Mann (1975) showed how annual capital investment flows could be represented by capital stock in dynamic profit-maximization models.

11 NRCS currently provides subsidies (cost-shares) of up to 75 percent to producers to adopt efficient irrigation systems such as subsurface drip irrigation in Texas. We assume that the irrigation industry responds to higher pumping costs and government subsidies as an 
Let $M_{i}(t)$ be the probability that a new more-efficient irrigation technology is developed by time $t$ when $M_{i}(0)=0$ and $0 \leq M_{i}(t) \leq 1$. The conditional probability of developing a technical innovation at time $t, m_{i}\left[z_{i}(t), K_{i}\left(t \mid k, g_{i}\right)\right]$, is the probability that development of such an innovation will occur during the next time period, $t+\Delta t$, given that it had not been developed at time $t$. The probability that development of a technical innovation occurring by time $t$ is then represented as

$$
M_{i}(t)=1-\exp \left[-b_{i} m_{i}\left(z_{i}(t), K_{i}\left(t \mid k, g_{i}\right)\right)\right] t
$$

where $b_{i}=1 /(1+\varphi)$ and $\varphi$ is the time elasticity of the hazard rate. ${ }^{12}$ The probability density function, which is obtained by differentiating equation 9 with respect to time variable $t$, is then written as a state equation:

$$
\frac{\partial M_{i}(t)}{\partial t}=m_{i}\left[z_{i}(t), K_{i}\left(t \mid k, g_{i}\right)\right]\left(1-M_{i}(t)\right)
$$

where

$$
m_{i}(t=0)=0, \partial m_{i} / \partial z_{i}>0, \partial m_{i} / \partial K_{i}>0, t \neq 0
$$

is the probability density function for development of the induced irrigation technology.

Once technical innovation occurs at time $t^{*}$, the economic and environmental benefits associated with use of IW and NF depend largely on whether the technology is adopted.

\section{Adoption}

Once an induced technology is developed, its adoption may be delayed if it does not provide a greater net economic benefit $\left(\pi_{i}\right)$ than use of the conventional technology $\left(\pi_{0}\right)$. Burness and Brill (2001) and Ashwell and Peterson (2013) considered models of adoption of an improved irrigation technology by producers without development of a new irrigation technology, and Shah, Zilberman, and Chakravorty (1995) considered the process of adoption of an irrigation technology without considering capital investments.

\footnotetext{
indication of society's willingness to pay to improve farm incomes and avoid over-exploitation of ground water and nonpoint-source contamination of ground water.

12 The time elasticity of the hazard rate, $\varphi$, is an unknown parameter, but it can be derived from an estimated hazard function.
} 
Let $V_{i}(\theta)$ be the probability of adoption of the $i$ th induced irrigation technology developed at time $\theta \geq t^{*}$ where $V_{i}\left(\theta=t^{*}\right) \geq 0$ and $0 \leq V_{i}(\theta) \leq 1$. A producer's decision to adopt an improved irrigation system depends on how much the cost of pumping ground water is rising $(m c(\theta))$, the amortized annual capital costs associated with adoption and maintenance of the new system $\left(z_{i}(\theta)\right)$, the government subsidy rate $\left(g_{i}\right)$, and the cost of any consultants needed to learn how to operate the new system $(E(\theta))$. Since the agricultural irrigation industry is largely unregulated and lacks independent design standards for irrigation systems (Center for Irrigation Technology 2015), most agricultural irrigators do not have the expertise necessary to determine if the system will perform as claimed. Therefore, agricultural irrigators must be trained to use new systems.

The conditional probability of adopting a new ith irrigation technology at time $\theta$,

$$
v_{i}\left[E(\theta), m c(\theta),\left(1-g_{i}\right) z_{i}(\theta) \mid \pi_{i}>\pi_{0}\right]
$$

is the probability that adoption of such an innovation will occur during the next time period, $\theta+\Delta \theta$, given that the new technology had not been adopted at time $\theta$ where $\pi_{i}$ is the expected profit resulting from adoption of the technology. We also assume that time of adoption of an innovation is uncertain and that the likelihood of adoption can be expressed as

$$
V_{i}(\theta)=1-\exp \left[-\sigma_{i} v_{i}\left(E(\theta), m c(\theta),\left(1-g_{i}\right) z_{i}(\theta) \mid \pi_{i}>\pi_{0}\right)\right] \theta
$$

where $\sigma_{i}=1 /(1+\psi)$ and $\psi$ is the time elasticity of the hazard rate.

The probability density function, $\partial V_{i}(\theta) / \partial \theta$, which is obtained from equation 11 , is represented as a state equation in our model as

$$
\frac{\partial V_{i}(\theta)}{\partial \theta}=v_{i}\left[E(\theta), m c(\theta),\left(1-g_{i}\right) z_{i}(\theta) \mid \pi_{i}>\pi_{0}\right]\left[1-V_{i}(\theta)\right]
$$

where $v_{i}\left(\theta=t^{*}\right)=0$ and

$$
\frac{\partial v_{i}}{\partial E}<0, \frac{\partial v_{i}}{\partial m c}>0, \frac{\partial v_{i}}{\partial z_{i}}<0, \text { and } \frac{\partial v_{i}}{\partial g_{i}}>0 .
$$

Equation 10, associated with development of an induced irrigation technology, and equation 12, associated with adoption of the technology, are then incorporated as state equations into a nested optimal control model of ground water and nitrate stock management. 


\section{Dynamic Model of Irrigation and Nitrogen Fertilizer Applications}

Applications of NFs by farmers generate both economic benefits, as shown in equation 6, and ground water pollution as an externality. In shallow aquifers underlying highly permeable soils, fertilizer applications and corresponding nitrate leaching can be assumed as simultaneous without loss. In areas where the farm land is above deep aquifers that have low permeability, one can expect that there will be a long time lag between application of the fertilizer and corresponding contamination of the ground water. Estimates of the contamination externality that ignore the time lag may underestimate the user cost associated with stock of nitrates in the aquifer (Kim, Hostetler, and Amacher 1993, Nkonya and Featherstone 2000).

Since nitrates are transported to the aquifer in soluble form through IW, we model changes in the stock of nitrates in the aquifer as

$$
\begin{aligned}
\dot{N}(t) \approx & \left(1-\alpha_{0}\right)\left[n_{0}(t-\tau)+f_{0} N(t-\tau)\right]+\left(1-\alpha_{i}\right)\left[n_{i}(t-\tau)\right. \\
& \left.+f_{i} N(t-\tau)\right]-\left\{f_{0}+f_{i}+\rho\right\} N(t)
\end{aligned}
$$

where $\alpha_{0}$ and $\alpha_{i}$ are the rate of irrigation efficiency of the conventional irrigation system and the $i$ th induced irrigation technology, respectively, and $\alpha_{i}(i \neq 0)>$ $\alpha_{0}, \tau$ is a time lag; ${ }^{13} f_{0} N(t)$ and $f_{i} N(t)$ are the amounts of nitrate removal from the aquifer through irrigation with the conventional and ith irrigation technology (i.e., nutrient recycle), respectively; and $\rho$ is the net natural discharge rate and denitrification.

Similarly, the hydrologic differential equation is represented by

$$
\dot{h}(t) \approx\left(\frac{R+\left[\left(1-\alpha_{0}\right) W_{0}(t-\tau)-W_{0}(t)\right]+\left[\left(1-\alpha_{i}\right) W_{i}(t-\tau)-W_{i}(t)\right]}{A S}\right)
$$

where $h(t)$ represents how many feet the water table is above sea level, $R$ is the natural recharge rate, $A$ is the number of acres over the aquifer, $S$ is the storativity coefficient, and $W_{0}$ and $W_{i}$ are the amount of IW applied with the conventional and $i$ th irrigation technologies, respectively.

Since adoption of an induced irrigation technology can occur only after the technology is developed, the expected action-value function (EV) associated with ground water management to be maximized for use of IW and NF under uncertain dates of development and adoption can be represented by a nested

\footnotetext{
13 We assume that the time lags associated with return flows of IW and leaching of nitrate are the same for the conventional and the induced irrigation technologies.
} 
action-value function as follows (Kim et al. 2010, Lewandrowski, Kim, and Aillery 2014): ${ }^{14}$

$$
\begin{aligned}
\operatorname{Max} E V= & \int_{0}^{T} e^{-\delta t}\left\{\left(1-M_{i}(t)\right)\left[N B\left(W_{0}(t)\right)+N B\left(n_{0}(t)\right)\right]\right. \\
& +M_{i}(t)\left[V_{i}(t)\left\{N B\left(W_{i}(t)\right)+N B\left(n_{i}(t)\right)-\left(1-g_{i}\right) z_{i}\right\}\right. \\
& \left.\left.+\left(1-V_{i}(t)\right)\left\{N B\left(W_{0}(t)\right)+N B\left(n_{0}(t)\right)\right\}\right]\right\} d t \\
= & \int_{0}^{T} e^{-\delta t}\left\{\left[N B\left(W_{0}(t)\right)+N B\left(n_{0}(t)\right)\right]\right. \\
& +M_{i}(t) V_{i}(t)\left[N B\left(W_{i}(t)\right)\right. \\
& \left.\left.+N B\left(n_{i}(t)\right)-\left(1-g_{i}\right) z_{i}-N B\left(W_{0}(t)\right)-N B\left(n_{0}(t)\right)\right]\right\} d t
\end{aligned}
$$

where

$$
\begin{aligned}
N B\left(W_{0}(t)\right)= & \left\{P_{y} \alpha_{0}^{2}\left[a_{1}+a_{5} \alpha_{0}\left(n_{0}(t)+f_{0} N(t)\right)\right]-k(S L-h(t))\right\} W_{0}(t) \\
& -P_{y} \alpha_{0}^{3} a_{2} W_{0}^{2}(t) \\
N B\left(n_{0}(t)\right)= & \left\{P_{y} \alpha_{0}^{2}\left[a_{3}+a_{5} \alpha_{0} W_{0}(t)-2 a_{4} \alpha_{0} f_{0} N(t)\right]-q\right\} n_{0}(t) \\
& -P_{y} \alpha_{0}^{3} a_{4} n_{0}^{2}(t) \\
N B\left(W_{i}(t)\right)= & \left\{P_{y} \alpha_{i}^{2}\left[a_{1}+a_{5} \alpha_{i}\left(n_{i}(t)+f_{i} N(t)\right)\right]-k(S L-h(t))\right\} W_{i}(t) \\
& -P_{y} \alpha_{i}^{3} a_{2} W_{i}^{2}(t) \\
N B\left(n_{i}(t)\right)= & \left\{P _ { y } \alpha _ { i } ^ { 2 } \left[a_{3}+a_{5} \alpha_{i} W_{i}(t)\right.\right. \\
& \left.\left.-2 a_{4} \alpha_{i} f_{i} N(t)\right]-q\right\} n_{i}(t)-P_{y} \alpha_{i}^{3} a_{4} n_{i}^{2}(t)
\end{aligned}
$$

and $T$ is terminal time, $\delta$ is the rate of discount, $k(S L-h(t))$ is the marginal pumping cost per acre where $k$ is a constant pumping cost per acre-foot of ground water per foot of lift, $S L$ is the elevation in feet of land above sea level, and $q$ is the unit price of NF.

The expected action-value function in equation 15, which measures the present value of the expected net benefit from use of IW and NF, assumes that the induced technology is developed with probability $M_{i}(t)$ and is subsequently adopted with probability $V_{i}(t)$ while the probability of using the conventional irrigation technology is $\left(1-V_{i}(t)\right)$.

The dynamic optimization problem of maximizing the expected net social welfare of use of ground water and NF in the presence of development and

14 See Sutton and Barto (1998) for the action-value function. 
adoption of an induced irrigation technology with uncertainty is expressed by maximizing the action-value function in equation 15 subject to the state equations, 10,12, 13, and 14. The current-value Hamiltonian equation is then presented as

$$
\begin{aligned}
H= & \left\{\left[N B\left(W_{0}(t)\right)+N B\left(n_{0}(t)\right)\right]+M_{i}(t) V_{i}(t)\left[N B\left(W_{i}(t)\right)+N B\left(n_{i}(t)\right)\right.\right. \\
& \left.\left.-\left(1-g_{i}\right) Z_{i}-N B\left(W_{0}(t)\right)-N B\left(n_{0}(t)\right)\right]\right\} \\
& +\frac{\lambda_{1}(t)}{A * S}\left\{R+\left[\left(1-\alpha_{0}\right) W_{0}(t-\tau)-W_{0}(t)\right]+\left[\left(1-\alpha_{i}\right) W_{i}(t-\tau)-W_{i}(t)\right]\right\} \\
+ & \lambda_{2}(t)\left\{\left(1-\alpha_{0}\right)\left[n_{0}(t-\tau)+f_{0} N(t-\tau)\right]\right. \\
+ & \left.\left(1-\alpha_{i}\right)\left[n_{i}(t-\tau)+f_{i} N(t-\tau)\right]-\left[f_{0}+f_{i}+\rho\right] N(t)\right\} \\
+ & \lambda_{3}(t)\left\{m_{i}\left[Z_{i}(t), K_{i}\left(t \mid k, g_{i}\right)\right]\left[1-M_{i}(t)\right]\right\} \\
+ & \lambda_{4}(t)\left\{v_{i}\left[E_{i}(\tau), m c(\tau),\left(1-g_{i}\right) z_{i}(\tau) \mid \pi_{i}>\pi_{0}\right]\left[1-V_{i}(\tau)\right]\right\} \\
& h(t)=h_{0} \text { for }-\tau \leq t \leq 0 \\
& \quad N(t)=\tilde{N}_{0} \text { for }-\tau \leq t \leq 0 \\
& M_{i}(t)=0 \text { for }-\tau \leq t \leq 0 \\
& V_{i}(t)=0 \text { for }-\tau \leq t \leq 0
\end{aligned}
$$

where $W_{0}(t), W_{i}(t), n_{0}(t), n_{i}(t)$, and $g_{i}$ are control variables; $h(t), N(t), M_{i}(t)$, and $V_{i}(t)$ are state variables; and $\lambda_{1}(t), \lambda_{2}(t), \lambda_{3}(t)$, and $\lambda_{4}(t)$ are adjoint variables associated with $h(t), N(t), M_{i}(t)$, and $V_{i}(t)$, respectively.

The necessary conditions for control variables are presented in equations 17-1 through 19 (the optimality conditions for the state and adjoint variables are presented in Appendix A, which is available from the authors). ${ }^{15}$

$$
\frac{\partial H}{\partial W_{0}(t)}+\frac{\partial H}{\partial W_{0}(t-\tau)} \mid(t+\tau)=0 \text { for } 0 \leq t<T-\tau,
$$

which implies that

$$
\begin{aligned}
\left(1-M_{i}(t) V_{i}(t)\right)\left[P_{w_{0}}-k(S L-h(t))+\frac{\partial B\left(n_{0}(t)\right)}{\partial W_{0}(t)}\right]=\frac{\lambda_{1}(t)}{A * S} \\
-\frac{\left(1-\alpha_{0}\right) \lambda_{1}(t+\tau)}{A * S}
\end{aligned}
$$

\footnotetext{
15 We assumed a weaker version of sufficient conditions to assure optimality (see Stengel (1994)).
} 
(17-2)

$\frac{\partial H}{\partial W_{0}(t)}=0$ for $T-\tau \leq t \leq T$,

which implies that

$$
\left(1-M_{i}(t) V_{i}(t)\right)\left[P_{w_{0}}-k(S L-h(t))+\frac{\partial B\left(n_{0}(t)\right)}{\partial W_{0}(t)}\right]=\frac{\lambda_{1}(t)}{A * S}
$$

$$
\frac{\partial H}{\partial W_{i}(t)}+\frac{\partial H}{\partial W_{i}(t-\tau)} \mid(t+\tau)=0 \text { for } 0 \leq t<T-\tau,
$$

which implies that

$$
\begin{gathered}
\left(M_{i}(t) V_{i}(t)\right)\left[P_{w_{i}}-k(S L-h(t))+\frac{\partial B\left(n_{i}(t)\right)}{\partial W_{i}(t)}\right]=\frac{\lambda_{1}(t)}{A * S} \\
-\frac{\left(1-\alpha_{i}\right) \lambda_{1}(t+\tau)}{A * S}
\end{gathered}
$$

(17-4)

$$
\frac{\partial H}{\partial W_{i}(t)}=0 \text { for } t-\tau \leq t \leq T,
$$

which implies that

$$
\left(M_{i}(t) V_{i}(t)\right)\left[P_{w_{i}}-k(S L-h(t))+\frac{\partial B\left(n_{i}(t)\right)}{\partial W_{i}(t)}\right]=\frac{\lambda_{1}(t)}{A * S}
$$

(18-1)

$$
\frac{\partial H}{\partial n_{0}(t)}+\frac{\partial H}{\partial n_{0}(t+\tau)} \mid(t+\tau)=0 \text { for } 0 \leq t<T-\tau,
$$

which implies that

$$
\left(1-M_{i}(t) V_{i}(t)\right)\left[P_{n_{0}}-q+\frac{\partial B\left(W_{0}(t)\right)}{\partial n_{0}(t)}\right]=-\left(1-\alpha_{0}\right) \lambda_{2}(t+\tau)
$$

$$
\frac{\partial H}{\partial n_{0}(t)}=0 \text { for } T-\tau \leq t \leq T,
$$

which implies that

$$
\left(1-M_{i}(t) V_{i}(t)\right)\left[P_{n_{0}}-q+\frac{\partial B\left(W_{0}(t)\right)}{\partial n_{0}(t)}\right]=0
$$




$$
\frac{\partial H}{\partial n_{i}(t)}+\frac{\partial H}{\partial n_{i}(t-\tau)} \mid(t+\tau)=0 \text { for } 0 \leq t<T-\tau,
$$

which implies that

$$
M_{i}(t) V_{i}(t)\left[P_{n_{i}}-q+\frac{\partial B\left(W_{i}(t)\right)}{\partial n_{i}(t)}\right]=-\left(1-\alpha_{i}\right) \lambda_{2}(t+\tau)
$$

$$
\frac{\partial H}{\partial n_{i}(t)}=0 \text { for } T-\tau \leq t \leq T,
$$

which implies that

$$
M_{i}(t) V_{i}(t)\left[P_{n_{i}}-q+\frac{\partial B\left(W_{i}(t)\right)}{\partial n_{i}(t)}\right]=0
$$

$$
\frac{\partial H}{\partial g_{i}}=0 \text { for } 0 \leq t \leq T,
$$

which implies that

$$
\begin{aligned}
& M_{i}(t) V_{i}(t) z_{i}+\left\{\left[1-M_{i}(t)\right] V_{i}(t)\left(b_{i} t\left(\frac{\partial m_{i}(t)}{\partial g_{i}}\right)\right)\right. \\
& \left.+M_{i}(t)\left[1-V_{i}(t)\right] \sigma_{i} t\left(\frac{\partial v_{i}(t)}{\partial g_{i}}\right)\right\}\left[B\left(W_{i}(t)\right)+B\left(n_{i}(t)\right)\right. \\
& \left.-B\left(W_{0}(t)\right)-B\left(n_{0}(t)\right)\right] \\
& =-\lambda_{3}(t)\left(1-M_{i}(t)\right)\left[1-b_{i} m_{i} t\right]\left(\frac{\partial m_{i}(t)}{\partial g_{i}}\right) \\
& -\lambda_{4}(t)\left(1-V_{i}(t)\right)\left[1-\sigma_{i} v_{i} t\right]\left(\frac{\partial v_{i}(t)}{\partial g_{i}}\right)
\end{aligned}
$$

The economic interpretation of optimal conditions presented in equations 17-1 through 19 is better served by first explaining the adjoint variables $\lambda_{1}(t)$ through $\lambda_{4}(t)$, which are presented in Appendix B (available from the authors). Adjoint variable $\lambda_{1}(t)$, which measures the marginal contribution of state variable $h(t)$ to the expected action-value function in equation 15, is positive, as shown in equation B.1. As the level of the water table in feet rises, the pumping cost to producers declines and the net economic benefit increases. Adjoint variable $\lambda_{2}(\mathrm{t})$, which measures the marginal contribution of state variable $N(t)$ to the expected action-value function, is negative, as shown in equation B.2. Since the nitrates available in the IW and the NF are perfect substitutes, producers reduce their applications of NF when the nitrates 
available in ground water increase. Therefore, the economic benefit from use of NF declines when greater amounts of nitrates are available from the IW at no cost. This result indicates that economic and environmental benefits increase as the stock of nitrates in the ground water is reduced by adoption of an improved irrigation technology.

Adjoint variable $\lambda_{4}(t)$ in equation B.4, which measures the marginal contribution of state variable $V_{i}(t)$ to the expected action-value function associated with an increase in the probability of adopting a new improved irrigation technology, is positive. This result, however, requires that adjoint variable $\lambda_{3}(t)$ in equation B.3, which measures the marginal contribution of state variable $M_{\mathrm{i}}(t)$ to the expected action-value function associated with an increase in the probability of developing an improved irrigation technology, is positive. Adoption of an improved irrigation technology, therefore, requires that the associated net economic benefit over time be greater than the benefit accrued by use of the conventional irrigation technology. With this knowledge regarding the adjoint variables, we can interpret the optimal conditions presented in equations 17-1 through 19.

Since IW and NF are complementary inputs in crop production, the results in equations 17-1 (conventional) and 17-3 (induced new technology) illustrate that efficient use of ground water for irrigation requires the sum of the expected marginal net economic benefit from use of IW and increase in the amount of complementary NF used to equal the cost associated with use of ground water minus the cost associated with delayed return flows of ground water. The results show, therefore, that models that do not consider development and adoption of an improved irrigation technology overestimate the marginal net economic benefit, and models that do not consider the time lag associated with return flows underestimate the cost of using ground water, which leads to a greater use of ground water than is optimal for irrigation.

Equations 17-2 and 17-4 show how, at the terminal time period, the marginal net economic benefit from use of IW is overstated when development and adoption of an irrigation technology is not considered, causing producers to use more ground water than is optimal for irrigation.

Equations 18-1 (conventional technology) and 18-3 (improved technology) show that the expected net economic benefit from use of NF must equal the user cost when incorporating the time lags associated with return flows and leaching. When development and adoption of an improved irrigation technology are not considered, the marginal net economic benefit from use of NF would be overstated, and the user cost would be overstated when failing to account for the time lag associated with nitrate leaching. Equations 18-2 and 184 demonstrate that efficient use of NF in the terminal period under each irrigation technology requires that the marginal benefit from use of $\mathrm{NF}$ equals the marginal cost of use.

We find that the economic properties of the optimal government subsidy are more complex than prior studies have considered. Equation 19 shows that, under the optimal government subsidy to encourage producers to adopt an 
induced irrigation technology, the sum of (i) the expected price of the induced irrigation system, (ii) the expected foregone benefit from failing to develop it, and (iii) the expected foregone benefit from failing to adopt it equals the sum of (i) the user cost from failing to develop the system and (ii) the user cost to adopt a new technology.

\section{Effects of a Cost-share Program on Ground Water Exploitation and Nitrate Stocks}

Using the optimal conditions of use of IW and NF in equations 17-1 and 18-4, we evaluate the effects of a cost-share program on use of IW and NF. The government subsidy $\left(g_{i}\right)$ to encourage producers to adopt better irrigation systems was treated as a control variable in the preceding section (see equation 19). To gain qualitative insight into the properties of optimal decision rules, we must discuss how the subsidy affects the cost to the user associated with nitrate and ground water stocks over time. Therefore, we now treat the government subsidy to producers as an exogenous variable. Though comparative dynamic analyses can be used to evaluate expected changes in the shadow values, $\lambda_{1}$ through $\lambda_{4}$ (Kim et al. 1996), such an analysis is needlessly complex, and we therefore use a simpler approach to evaluate the effects of a government subsidy.

For convenience, we let the time lag, $\tau$, be zero in equations 17-1 (conventional irrigation) and 17-3 (improved irrigation). The cost of pumping ground water is then represented as

$$
\begin{aligned}
\lambda_{1}(t)= & \frac{(A S)}{2}\left\{\left[\frac{\left.P_{w_{0}}-k(S L-h(t))+\frac{\partial B\left(n_{0}(t)\right)}{\partial W_{0}(t)}\right]}{\alpha_{0}}\right]\right. \\
& +\left(M_{i}(t) V_{i}(t)\right)\left[\left(\frac{P_{w_{i}}-k(S L-h(t))+\frac{\partial B\left(n_{i}(t)\right)}{\partial W_{i}(t)}}{\alpha_{i}}\right)\right. \\
& \left.\left.-\left(\frac{P_{w_{0}}-k(S L-h(t))+\frac{\partial B\left(n_{0}(t)\right)}{\partial W_{0}(t)}}{\alpha_{0}}\right)\right]\right\}
\end{aligned}
$$

Similarly, the cost associated with nitrate stocks in ground water is obtained from equations 18-1 (traditional irrigation) and 18-3 (improved irrigation) under the assumption that $\tau=0$ : 
(21)

$$
\begin{aligned}
\lambda_{2}(t)= & -\left[\frac{\left(P_{n_{0}}-q+\frac{\partial B\left(W_{0}(t)\right)}{\partial n_{0}(t)}\right)}{2\left(1-\alpha_{0}\right)}\right]+\frac{\left(M_{i}(t) V_{i}(t)\right)}{2} \\
& \left\{\left(\frac{P_{n_{0}}-q+\frac{\partial B\left(W_{0}(t)\right)}{\partial n_{0}(t)}}{\left(1-\alpha_{0}\right)}\right)-\left(\frac{P_{n_{i}}-q+\frac{\partial B\left(W_{i}(t)\right)}{\partial n_{i}(t)}}{\left(1-\alpha_{i}\right)}\right)\right\} .
\end{aligned}
$$

Inserting equations 9 and 11 for $M_{i}(t)$ and $V_{i}(t)$, respectively, into equations 20 and 21 and then differentiating the resulting equations with respect to the rate of the government subsidy, $g_{i}$, results in

$$
\begin{aligned}
\frac{\partial \lambda_{1}(t)}{\partial g_{i}}= & \frac{(A S)}{2}\left[\left(\frac{P_{w_{i}}-k(S L-h(t))+\frac{\partial B\left(n_{i}(t)\right)}{\partial W_{i}(t)}}{\alpha_{i}}\right)\right. \\
& \left.-\left(\frac{P_{w_{0}}-k(S L-h(t))+\frac{\partial B\left(n_{0}(t)\right)}{\partial W_{0}(t)}}{\alpha_{0}}\right)\right] \\
& \times\left[V_{i}(t)\left(1-M_{i}(t)\right) b_{i} t\left(\frac{\partial m_{i}}{\partial g_{i}}\right)+M_{i}(t)\left(1-V_{i}(t)\right) \sigma_{i} t\left(\frac{\partial v_{i}}{\partial g_{i}}\right)\right] \\
& >=<0 .
\end{aligned}
$$

$$
\begin{aligned}
\frac{\partial \lambda_{2}(t)}{\partial g_{i}}= & \frac{1}{2}\left[\left(\frac{P_{n_{0}}-q+\frac{\partial B\left(W_{0}(t)\right)}{\partial n_{0}(t)}}{\left(1-\alpha_{0}\right)}\right)-\left(\frac{P_{n_{i}}-q+\frac{\partial B\left(W_{i}(t)\right)}{\partial n_{i}(t)}}{\left(1-\alpha_{i}\right)}\right)\right] \\
& \times\left[V_{i}(t)\left(1-M_{i}(t)\right) b_{i} t\left(\frac{\partial m_{i}}{\partial g_{i}}\right)+M_{i}(t)\left(1-V_{i}(t)\right) \sigma_{i} t\left(\frac{\partial v_{i}}{\partial g_{i}}\right)\right] \\
& >=<0 .
\end{aligned}
$$

The marginal effect of the government subsidy on the cost associated with ground water and the nitrate stock in the aquifer are obtained from equations 22 and 23, respectively, as follows. 


$$
\frac{\partial \lambda_{1}(t)}{\partial g_{i}}>=<0 \quad \text { if } \quad\left(\frac{\alpha_{i}}{\alpha_{0}}\right)<=>\left(\frac{P_{w_{i}}-k(S L-h(t))+\frac{\partial B\left(n_{i}(t)\right)}{\partial W_{i}(t)}}{P_{w_{0}}-k(S L-h(t))+\frac{\partial B\left(n_{0}(t)\right)}{\partial W_{0}(t)}}\right)
$$

$$
\frac{\partial \lambda_{2}(t)}{\partial g_{i}}>=<0 \quad \text { if } \quad\left(\frac{1-\alpha_{i}}{1-\alpha_{0}}\right)>=<\left(\frac{P_{n_{i}}-q+\frac{\partial B\left(W_{i}(t)\right)}{\partial n_{i}(t)}}{P_{n_{0}}-q+\frac{\partial B\left(W_{0}(t)\right)}{\partial n_{0}(t)}}\right)
$$

Equation 24 shows that the user cost associated with the ground water stock increases (decreases) as the rate of the government subsidy increases when the rate of increase in irrigation efficiency is less than (greater than) the rate of increase in the marginal net economic benefit resulting from adoption of an improved irrigation technology. When the rate of increase in the marginal net economic benefit is greater than the rate of increase in irrigation efficiency, producers use more IW and the user cost associated with the ground water stock increases. Most earlier empirical studies (e.g., Huffaker and Whittlesey 2003, Pfeiffer and Lin 2014) support this outcome, finding that adoption of an induced irrigation technology can lead to a greater use of ground water because some producers switch to high-value crops and/or convert from dryland production to irrigated production. However, when the rate of increase in irrigation efficiency is greater than the rate of increase in the marginal net economic benefit, less water is used relative to an inefficient irrigation system because some producers invest more capital in IW to drive down the marginal net economic benefit. This result is partially supported by Peterson and Ding (2005).

Similarly, equation 25 shows that the user cost associated with the nitrate stocks in the aquifer decreases (increases) as the rate of the government subsidy increases when the rate of increase in the marginal net economic benefit from adoption of an improved irrigation technology is greater than the rate of reduction of nitrate leaching. In that case, producers use a greater amount of nitrates so the user cost associated with the nitrate stocks in the ground water declines (becomes more negative) as the subsidy rate increases. This result is consistent with several earlier studies (Shaffer, Halvorson, and Pierce 1991, Wu et al. 1994). It suggests that a reduction in pollution by adoption of an induced irrigation technology could lead to an increase in the nitrate stocks because of the endogenous technological change. When the rate of reduction in nitrate leaching is greater than the rate of increase in the marginal net economic benefit, producers use less nitrates and the user cost increases (becomes less negative), as demonstrated by Kim, Schaible, and Daberkow (2000). 
Table 1. Revenues, Pumping Costs, and Net Benefits by Well Capacity and System Type

\begin{tabular}{|c|c|c|c|c|c|c|}
\hline & \multicolumn{3}{|c|}{$\begin{array}{l}300 \text { Gallon per Minute } \\
\text { Well Capacity }\end{array}$} & \multicolumn{3}{|c|}{$\begin{array}{l}500 \text { Gallon per Minute } \\
\text { Well Capacity }\end{array}$} \\
\hline & Flood & Sprinkler & Drip & Flood & Sprinkler & Drip \\
\hline Application efficiency & 0.60 & 0.75 & 1.00 & 0.60 & 0.75 & 1.00 \\
\hline $\begin{array}{l}\text { Seasonal irrigation } \\
\text { (acre-feet) }\end{array}$ & 1.35 & 1.61 & 1.27 & 1.97 & 2.00 & 1.91 \\
\hline $\begin{array}{l}\text { Consumptive seasonal } \\
\text { irrigation (acre- } \\
\text { feet) }\end{array}$ & 0.81 & 1.21 & 1.27 & 1.18 & 1.50 & 1.91 \\
\hline $\begin{array}{l}\text { Yield (bushels per } \\
\text { acre) }\end{array}$ & 118.32 & 146.87 & 150.35 & 147.15 & 167.58 & 183.37 \\
\hline $\begin{array}{l}\text { Revenue (dollars per } \\
\text { acre) }^{\mathrm{a}}\end{array}$ & 269.77 & 334.86 & 342.80 & 335.50 & 382.08 & 418.08 \\
\hline $\begin{array}{l}\text { Pumping cost (dollars } \\
\text { per acre) }\end{array}$ & 34.74 & 56.51 & 40.90 & 45.06 & 62.64 & 55.90 \\
\hline $\begin{array}{l}\text { Net revenue (dollars } \\
\text { per acre) }\end{array}$ & 235.03 & 278.35 & 301.90 & 290.44 & 319.44 & 362.18 \\
\hline $\begin{array}{l}\text { Average net economic } \\
\text { benefit (dollars per } \\
\text { acre-foot) }\end{array}$ & 174.10 & 172.89 & 237.72 & 147.43 & 159.72 & 189.62 \\
\hline $\begin{array}{l}\text { Water volume } \\
\text { pumped (acre- } \\
\text { feet) }\end{array}$ & 215.47 & 202.49 & 203.51 & 314.53 & 252.00 & 305.47 \\
\hline
\end{tabular}

${ }^{\mathrm{a}}$ Corn price of $\$ 2.28$ per bushel.

${ }^{\mathrm{b}}$ Acreages for the flood, sprinkler, and drip irrigation systems are based on 160, 126, and 160 acres, respectively.

Source: Peterson and Ding (2005).

\section{Numerical Illustration}

Most previous studies of conjunctive use of ground and surface water at the river-basin level employed mathematical programming models (Huffaker and Whittlesey 2003, Ward and Pulido-Velazquez 2008) or ground water management (Peterson and Ding 2005) to compare use of IW before and after adoption of an improved irrigation technology. To provide a numerical example that we could compare to our predictions, we obtained data from Peterson and Ding (2005), which studied the impact of an improvement in irrigation efficiency achieved by converting from flood to center-pivot and drip irrigation systems on conservation of ground water in western portions of the high plains in Kansas for continuous corn production (see Table 1). 
We find a rate of increase in irrigation efficiency of 1.25 for sprinkler irrigation and 1.67 for drip irrigation, a rate of increase in the marginal (average) net benefit for a 300-gallon-per-minute well capacity of 0.99 for sprinkler irrigation and 1.37 for drip irrigation, and a rate of increase in the marginal net benefit for a 500-gallon-per-minute well capacity of 1.08 for sprinkler irrigation and 1.29 for drip irrigation. These results show that the increase in the rate of irrigation efficiency is greater than the increase in the rate of marginal net benefit for both sprinkler and drip irrigation systems regardless of pumping capacity. Therefore, applications of water would decrease after adoption of an improved irrigation technology. Table 1 shows that water applications increase with sprinkler irrigation and decrease with drip irrigation as expected.

Pfeiffer and Lin (2014) also evaluated the effects of converting traditional center-pivot irrigation systems to highly efficient dropped-nozzle center-pivot systems on conservation of ground water in western Kansas. Their empirical results show that the shift to a more-efficient irrigation technology increased extraction of ground water, in part due to a shift to high-value crops that led to a higher marginal net economic benefit from the use of IW.

\section{Conclusions}

While the EQIP cost-share program is designed to protect aquifers from overexploitation and nonpoint-source pollution by inducing producers and irrigation enterprises to experiment with and develop new, more-efficient irrigation technologies, numerous empirical studies have shown that the program is unlikely to reduce either depletion of the aquifers or nonpointsource pollution. We revisit this issue by refining traditional models of ground water dynamics by incorporating (i) development and adoption of an induced irrigation technology, (ii) time lags associated with return flows of ground water and leaching of nitrates, and (iii) a more accurate representation of the economic benefits of use of IW and NF.

We find that the economic properties of the optimal cost-share program are considerably more complex than previous studies considered. The optimal government subsidy to encourage producers to adopt an induced irrigation technology requires that the sum of (i) the expected price of the induced irrigation system, (ii) the expected foregone benefit from failing to develop the new technology, and (iii) the expected foregone benefit from failing to adopt the new technology must equal the sum of the costs to the user of failing to develop and to adopt the new technology.

In summary, we find that the optimal irrigation and fertilization rates do not respond monotonically to changes in the efficiency of the irrigation system. Whether producers decrease (increase) IW and NF as they adopt improved irrigation technologies depends on whether the increase in the rate of irrigation efficiency is greater than (less than) the increase in the rate of the marginal net economic benefit. Therefore, we find that a greater use of water 
and fertilizer after adoption of an induced, more-efficient irrigation technology depends largely on whether producers switch to high-value crops.

\section{Supplementary Materials}

To view supplementary material for this article, please visit http://dx.doi.org/ 10.1017/age.2016.19

\section{References}

Ashwell, N.E.Q., and J.M. Peterson. 2013. "The Impact of Irrigation Capital Subsidies on Common-pool Groundwater Use and Depletion: Results for Western Kansas." Selected paper presented at the Agricultural and Applied Economics Association's annual meeting, Washington, DC.

Berck, P., and G. Helfand. 1990. "Reconciling the von Liebig and Differentiable Crop Production Functions." American Journal of Agricultural Economics 72(4): 985-996.

Bordovsky, J.P. 2015. Research scientist and agricultural engineer, Texas AgriLife Research, 823 West U.S. Highway 70, Plainview, TX 79072. Phone 806.889.3315. Email: j-bordovsky@tamu.edu. Personal communication.

Burness, H.S., and T.C. Brill. 2001. "The Role for Policy in Common Pool Groundwater Use." Resource and Energy Economics 23(1): 19-40.

Center for Irrigation Technology. 2015. "The Center for Irrigation Technology" webpage, www.fresnostate.edu/jcast/cit. CIT, Fresno, CA.

Hayami, Y., and V. Ruttan. 1985. Agricultural Development: An International Perspective. Baltimore, MD: Johns Hopkins University Press.

Huffaker, R., and N. Whittlesey. 2003. "A Theoretical Analysis of Economic Incentive Policies Encouraging Agricultural Water Conservation." Water Resources Development 19(1): 37-55.

Irrigation Association. 2015. Main web page, www.irrigation.org. Irrigation Association, Fairfax, VA.

Irrigation Technology Center. 2015. "The Irrigation Technology Center: Vision and Concept." ITC, College Station, TX. Available at http://itc.tamu.edu/documents/Brochure.pdf.

Kamien, M.I., and N. Schwartz. 1978. "Optimal Exhaustible Resource Depletion with Endogenous Technical Change." Review of Economic Studies 45(1): 179-196.

Kieffer, N.M. 1988. "Economic Duration Data and Hazard Functions." Journal of Economic Literature 26(2): 646-679.

Kim, C.S., J. Hostetler, and G. Amacher. 1993. "Regulation of Groundwater Quality with Delayed Responses." Water Resources Research 29(5): 1369-1377.

Kim, C.S., and G. Schaible. 2000. "Economic Benefits Resulting from Irrigation Water Use: Theory and an Application to Groundwater Use." Environmental and Resource Economics 17(1): 73-87.

Kim, C.S., G. Schaible, and S. Daberkow. 2000. "An Efficient Cost-sharing Program to Reduce Nonpoint-source Contamination: Theory and an Application to Groundwater Contamination." Environmental Geology 39(6): 649-659.

Kim, C.S., G. Schaible, J. Lewandrowski, and U. Vasavada. 2010. "Managing Invasive Species in the Presence of Endogenous Technological Change with Uncertainty." Risk Analysis 30(2): 250-260.

Kim, C.S., N. Uri, C. Sandretto, and I.W. Parry. 1996. “Endogenous Technological Change and Pollution Abatement." Environmental Geology 27(3): 191-197.

Kohli, U. 1983. “Non-joint Technologies.” Review of Economic Studies 50: 209-219. 
Lewandrowski, J., C.S. Kim, and M. Aillery. 2014. “Carbon Sequestration through Afforestation under Uncertainty." Forest Policy and Economics 38: 90-96.

Lichtenberg, E., J. Majsztrik, and M. Saavoss. 2015. "Grower Demand for Sensor-controlled Irrigation." Water Resources Research 51(1): 341-358.

Mann, D.H. 1975. "Optimal Theoretical Advertising Stock Models: A Generalization Incorporating the Effects of Delayed Response from Promotional Expenditure." Management Science 21(7): 823-832.

Natural Resources Conservation Service. 2014. "Subsurface Drip Irrigation: Conservation Today for Water Tomorrow." NRCS, U.S. Department of Agriculture, Washington, DC.

Nkonya, E.M., and A.M. Featherstone. 2000. "Determining Socially Optimal Nitrogen Application Rates Using a Delayed Response Model: The Case of Irrigated Corn in Western Kansas." Journal of Agricultural and Resource Economics 25(2): 453-467.

Peterson, J.M., and Y. Ding. 2005. "Economic Adjustments to Groundwater Depletion in the High Plains: Do Water-saving Irrigation Systems Save Water?” American Journal of Agricultural Economics 87(1): 147-159.

Pfeiffer, L., and C. Lin. 2014. "Does Efficient Irrigation Technology Lead to Reduced Groundwater Extraction? Empirical Evidence." Journal of Environmental Economics and Management 67(2): 189-208.

Romer, P.M. 1990. “Endogenous Technological Change.” Journal of Political Economics 98(5): S71-S102.

- 1994. "The Origins of Endogenous Growth." Journal of Economic Perspectives 8(1): 3-22.

Roseta-Palma, C. 2003. “Joint Quantity/Quality Management of Groundwater." Environmental and Resource Economics 26(1): 89-106.

Scheierling, S., R. Young, and G. Cardon. 2006. "Public Subsidies for Water-conserving Irrigation Investments: Hydrologic, Agronomic, and Economic Assessment." Water Resources Research 42(3): 1-11.

Shaffer, M.J., A.D. Halvorson, and F.J. Pierce. 1991. "Managing Nitrogen for Groundwater Quality and Farm Profitability." Soil Science Society of America 13: 285-322.

Shah, F.A., D. Zilberman, and U. Chakravorty. 1995. "Technology Adoption in the Presence of an Exhaustible Resource: The Case of Groundwater Extraction." American Journal of Agricultural Economics 77(2): 291-299.

Shumway, C., R. Pope, and E. Nash. 1983. "Allocatable Fixed Inputs and Jointness in Agricultural Production: Implications for Economic Modeling." American Journal of Agricultural Economics 65(1): 72-78.

Stengel, R. 1994. Optimal Control and Estimation (2nd edition). New York, NY: Dover Publication.

Sutton, R.S., and A.G. Barto. 1998. Reinforcement Learning: An Introduction. Cambridge, MA: MIT Press.

Ward, F.A., and M. Pulido-Velazquez. 2008. "Water Conservation in Irrigation Can Increase Water Use." Proceedings of the National Academy of Sciences 105(47): 18215-18220.

Wu, J.J., H.P. Mapp, and D.J. Bernardo. 1994. "Integrating Economic and Physical Models for Analyzing Water Quality Impacts of Agricultural Policies in the High Plains." Review of Agricultural Economics 18(3): 353-372.

Young, A. 1993. "Invention and Bounded Learning by Doing." Journal of Political Economics 101(3): 443-472. 